\title{
Object Shift in Akoose: Case Deficiency or Agreement Requirements?
}

\author{
Michael Etuge Apuge \\ The University of Maroua, Maroua, Cameroon
}

\begin{abstract}
Akoose exhibits light verbs, which have a nontrivial bearing on the resultant syntactic structures and word order in the language. In constructions involving the complex VP, the post-verbal NP undergoes object shift (OS) once a light verb is introduced in the structure. This process in turn changes the word order in the language from SVO to SOV, stranding the verb in sentence final position (leaving a transitive verb without its complement). The paper seeks to establish the rationale for OS in the language; the discussion is done within the framework of the Minimalist Program (Chomsky, 2000; 2001a; 2001b). The analysis shows that although case deficiency (Chomsky, 1981) of visible NPs seems to justify OS in some structures in Akoose, there remains a theoretical weakness in that, some apparent, ungrammatical cases are not accounted for by the Case Filter. It is therefore assumed that a solution to the problem posed by OS in the language can only be sought elsewhere. It is found that agreement requirements in light verb constructions in the language trigger OS; agreement links the probe and its goal via movement, and where agreement relations hold uninterpretable features of the relevant syntactic objects are valued for convergence.
\end{abstract}

Keywords: light verbs, case deficiency, object shift, agreement, Akoose

\section{Introduction}

This paper examines argument movement (A-Movement) and verb raising. The two movement operations are treated together because they are both attested in complex VP structures, and sometimes both a verb and an argument are displaced in a given structure. Movement of constituents within the complex VP structure in Akoose seems interesting because sometimes it is the external argument and the verb that move and sometimes it is the verb and the internal argument that get raised. It is argued that in such operations, the presence of the light verb is crucial to the raising of the main verb. It is further argued that if a light verb is introduced in a given structure and the object fails to shift, the SVO structure is preserved, but the relevant derivation is deviant. Before delving into the main argumentation therefore, it is expedient to first discuss the morphological form of light verbs since they have a significant bearing on key analyses of the paper. This is the focus in section two, and while lexical light verbs and movement are treated in section three, OS and the licensing conditions in these constructions are examined in section four.

\section{Morphological Forms of Akoose Lexical Light Verbs}

Lexical light verbs (henceforth LLvs) in Akoose consist of VP adverbs and some auxiliaries, as shown in

Michael Etuge Apuge, Ph.D., Associate Professor, Department of Bilingual Letters, University of Maroua. 
(1). ${ }^{1}$

(1) Lexical Light Verbs

a. VP Adverbs

(i) yóḱ் "often"

(ii) mentánć "used to"

(iii) sapé "first"

(iv) pŭn "almost"

b. (Modal) Auxiliaries

(i) dongáné "must"

(ii) téngáné "should"

LLvs in Akoose generally have some characteristics, as outlined in (2) below.

(2) Characteristics of LLvs in Akoose:

a. are free morphemes, but structurally dependent for meaning

b. trigger the raising of object NPs in infinite clauses

c. intervene between the subject and the shifted object

d. do not select independent internal arguments

LLvs have independent lexical meaning, even though they are also structurally dependent on main verbs in the relevant context for contextual meaning. For instance, $y$ oké in (3) has the independent meaning "often", but as observed in (3b) yók is structurally deficient because of the absence of a main verb in the example.

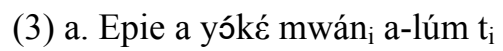

Epie agr often child to send

"Epie often sends the child".

b. *Epie a yóké mwán

Epie agr often child

The presence of these light verbs in Akoose, their distribution and relation to main verbs as well as their influence in the operations of object shift and verb raising pose a problem to the minimalist approach to the structure in the language. For instance, it has been established that there is a correlation between V-raising and object shift, and that object shift applies only when the verb raises out of VP as borne out in the Danish examples in (4) and (5) (Ouhalla, 1999). This claim became known as Holmberg's generalization. As the finite verb moves out of VP to $\mathrm{C}$ in (4b), the pronominal direct object also moves out of VP to a position just above VP (i.e. Spec, AgrOP). Conversely, the data in (5) show that when the main verb does not move out of the VP, the direct object does not undergo object shift either.

(4) a. Peter kØbte den ikke

Peter bought it not

"Peter did not buy it"

b. Peter kØbte den [vp ikke [vp ${ }^{t} \mathrm{k} \emptyset b t e . . .{ }^{t} \mathrm{den} .$.

(5) a. Hvorfor har Peter ikke kØbe den?

Why has Peter not bought it

“Why hasn't Peter bought it?

${ }^{1}$ For further discussion on auxiliary verbs in Akoose, see Hedinger (2008). 
b. Hvorfor har Peter [vp ikke [vp kØbe den ...

In Akoose however, the phenomenon of object shift obtains without the main verb raising, as shown in (6). This poses a theoretical problem to the analysis.

(6) a. Epie a-n lúm mwán

Epie sm P1 send child

"Epie sent the child"

b. Epie a yóké mwán $n_{i}$ a-lúm $t_{i}$

Epie sm often child to send

"Epie often sends the child".

From the foregoing argument, it is obvious that the Akoose facts require a different analysis. It is assumed here that the theoretical VP Shells can better handle the data. The focus now is to discuss the data and demonstrate the various movement operations that take place within the structures.

\section{Lexical Light Verbs and Movement}

The nature of object shift in Akoose vis à vis the difference in Holmberg's (1999) standard analysis of object shift presupposes some problems that the theory needs to handle in the language. Recall that lexical light verbs in Akoose include VP adverbs and auxiliaries. It is assumed that structures containing these verbs invariably trigger object shift. Research on object shift and studies relating to the syntax of verbs have been carried out on a number of languages (den Besten, 1983; Koopman, 1984; Torrego, 1984; Travis, 1984; Holmberg, 1986; Vikner, 1991; Lightfoot \& Hornstein, 1994; Ouhalla, 1999), among others. In treating lexical light verbs and movement, VP adverbs and object shift are examined in section (3.1), auxiliaries and object shift in section (3.2), object shift and the licensing condition in section (4.0).

\section{VP Adverbs and Object Shift}

The data in (7)-(10) are cases of single object constructions. Whereas the (a) examples of each set of the data exhibit simple VP structures, and their (b) and (c) counterparts show complex VP structures. The complex VP structures are due to the introduction of the lexical light verbs (yóké in (7), mentánć in (8), pǔn in (9), and sápé in (10) respectively).

(7) a. Epie a-n lúm mwán

Epie agr P1 send child

"Epie sent the child"

b. Epie a yóké mwán ${ }_{\mathrm{i}}$ a-lúm $\mathrm{t}_{\mathrm{i}}$

Epie agr often child to send

"Epie often sends the child".

c. *Epie a yóké a-lúm mwán

Epie agr often to send child

d. *Epie a yóké lúm mwán

Epie agr often send child

(8) a. Epie a n lím pòm

Epie agr P1 dig holes

"Epie dug holes" 
b. Epie a mentánć pòn $n_{\mathrm{i}}$ a-lím $\mathrm{t}_{\mathrm{i}}$

Epie agr use-to holes to dig

"Epie use to digs a hole"

c. *Epie a mentané à-lím pòn

Epie agr use-to to dig holes

d. *Epie a mentané lím pòn

Epie agr use-to dig holes

"*Epie used-to to dig holes"

(9) a. Epie a-n súm mbód

Epie agr P1 sell goat

"Epie sold a goat"

b. Epie a-n pǔn mbód $\mathrm{d}_{\mathrm{i}} \mathrm{a}$-súm $\mathrm{t}_{\mathrm{i}}$

Epie agr P1 almost goat sell

"Epie almost sold a goat"

c. *Epie a-n pǔn a-súm mbód

Epie agr P1 almost to sell goat

“*Epie almost to sell a goat"

d. *Epie a-n pŭn súm mbód

Epie agr P1 almost sell goat

"*Epie almost sell a goat"

(10) a. Epie a-n súm mbód

Epie agr P1 sell goat

"Epie sold a goat"

b. Epie a-n sápé mbód $\mathrm{d}_{\mathrm{i}} \mathrm{a}$-súm $\mathrm{t}_{\mathrm{i}}$

Epie agr P1 first goat to sell

"Epie first sold a goat"

c. *Epie a-n sápé a-súm mbód

Epie agr P1 first to sell goat

"*Epie first to sell a goat"

d. *Epie a-n sápé súm mbód

Epie agr P1 first sell goat

"*Epie first sell a goat"

Also, observe that the objects have raised in all the (b) examples of the data, as indicated by the traces and their corresponding indices on the moved objects. However, note the ungrammaticality of the cases in (c) and (d). The issue now is to account for this divergence. Let us focus on (7): (7a) is a straightforward and simple structure in that it has just a simple predicate and it does not involve movement. In (7b), (as shown in (11) below) a light verb is introduced and the verb form changes from lúm (i.e. finite as in (7a)) to a-lúm (infinite). 


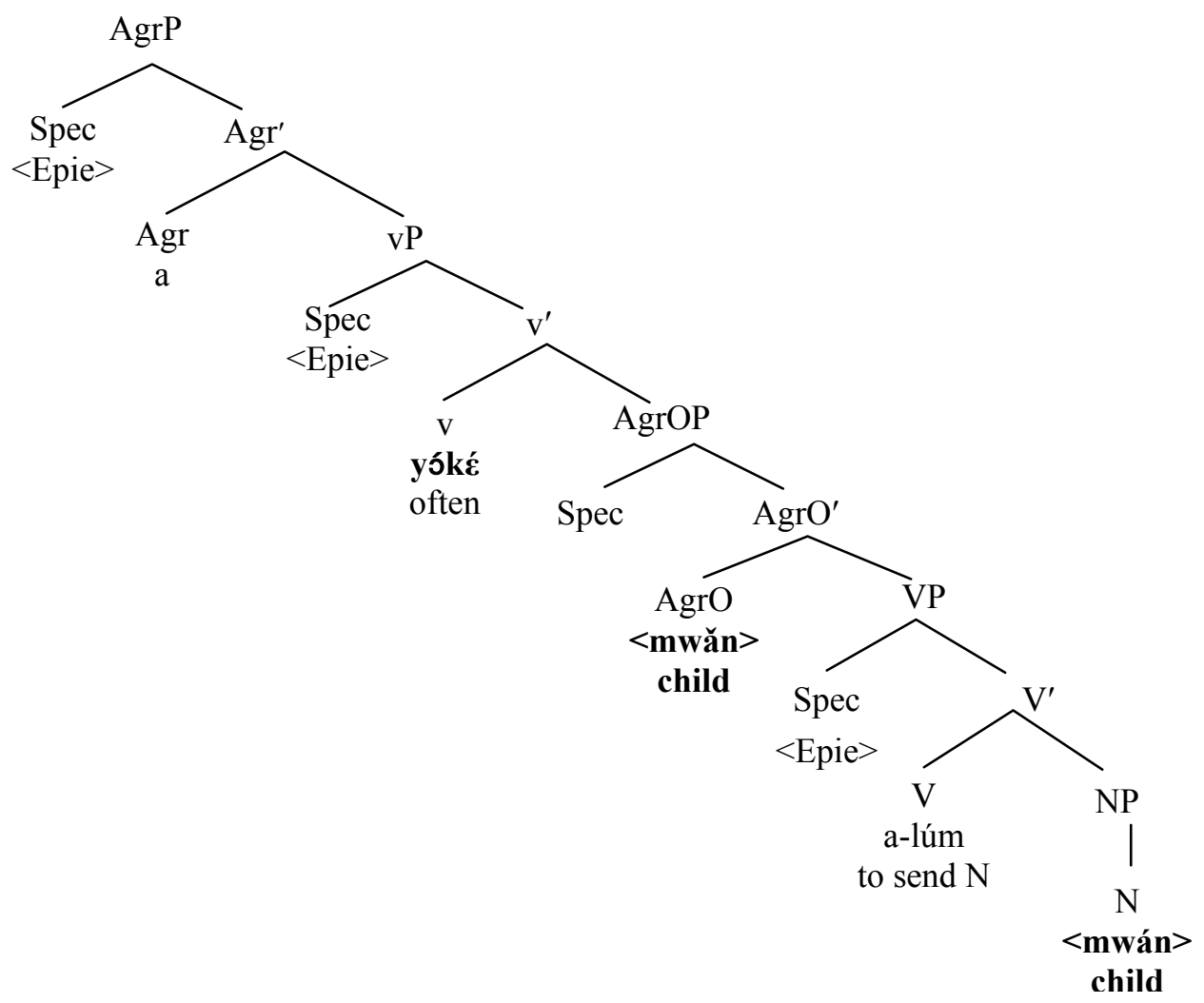

This operation triggers the object mwán to get raised to a position above VP but below vP (the light verb constituent). The ungrammaticality of (7c-d) is presumably because object shift (henceforth OS) fails to take place. This argument applies to all the items of the data.

The task now is to state the condition that licenses OS, and to explain the change in the verb form in such structures. Before attempting a theoretical explanation of these examples, it is important to first determine what obtains between auxiliaries and OS. The objective here is to find out whether auxiliaries affect the syntax differently from VP adverbs. This approach will also help to fully establish the facts on Akoose OS and to attain a logical, comprehensive and theoretical explanation of the phenomenon in the language.

\section{Auxiliaries and Object Shift}

The crucial auxiliaries here are dungáné "must" and téngáné "should". A critical analysis of the data in (12) and (13) reveals one important fact, namely that these auxiliaries affect the structures in the same way as the VP adverbs. In other words, (12a) and (13a) show an SVO order with no OS whereas the order in (12b) and (13b) is SOV with OS.

(12) a. Epie a n pím ntid

Epie agr P1 carry load

"Epie carried the load"

b. Epie a dungáné ntidi a-pím $\mathrm{t}_{\mathrm{i}}$

Epie agr must load to carry

"Epie must carry the load"

c. *Epie a dungáné a-pím ntid

Epie agr must to carry load 
d. *Epie a dungáné pím ntid

Epie agr must carry load

(13) a. Epie a n páál sábé

Epie agr P1 harvest orange

"Epie harvest an orange"

b. Epie a téngáné sabś $\varepsilon_{\mathrm{i}}$ a páál $t_{\mathrm{i}}$

Epie agr should orange to harvest

"Epie should harvest an orange"

c. *Epie a téngáné á-páál sabé

Epie agr should to harvest orange

d. *Epie a téngáné páál sabé

Epie agr should harvest orange

OS is triggered by the introduction of the light verbs, dungáné "must" and téngáné "should" in the respective structures. The ungrammaticality of the structures in (12) and (13) is presumably due to the fact that OS fails to take place. The challenge now is to advance an empirical argumentation with respect to the acceptability of the examples presented. In the next section therefore, the licensing condition(s) of A-movement and the theoretical implications of OS in constructions involving lexical light verbs are discussed.

\section{OS and the Licensing Conditions in LLv Constructions}

The lexical light verb in Akoose is inherently finite, and only finite verbs select objects for theta-marking and Accusative case assignment in the language. In other words, each argument receives only one theta role (in line with the theta criterion), and each visible NP must be assigned case (in line with the Case Filter). Accordingly, therefore, two finite verbs in a given structure must assign two theta roles to two separate arguments. Note that in some languages, infinitives may take objects, but this is not the case in Akoose. For instance, in English, as noted in (14) the object stays in the post-verbal position. Now, observe the Akoose examples in (15), the raising of the object in grammatical (15b) and the failure of OS in ungrammatical (15c) buttress the claim that infinitive verbs do not select objects in Akoose.

English:

(14) a. I eat food; b. I want to eat food; c. I wish to eat food

Akoose:

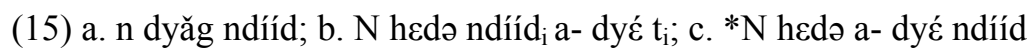

I eat food I want food to eat I want to eat food

"I am eating food" "I want to eat food"

To adequately explain the data and to put the theoretical account on a concrete footing, it is important to consider some examples seen earlier, which are discussed below. Assume the example in (16a). Note that only a finite verb is present, but no movement operation is involved as the object remains in-situ. This is illustrated in the schema in (16b) below.

(16) a. Epie a-n lúm mwán

Epie agr P1 send child

"Epie sent the child"

b. 


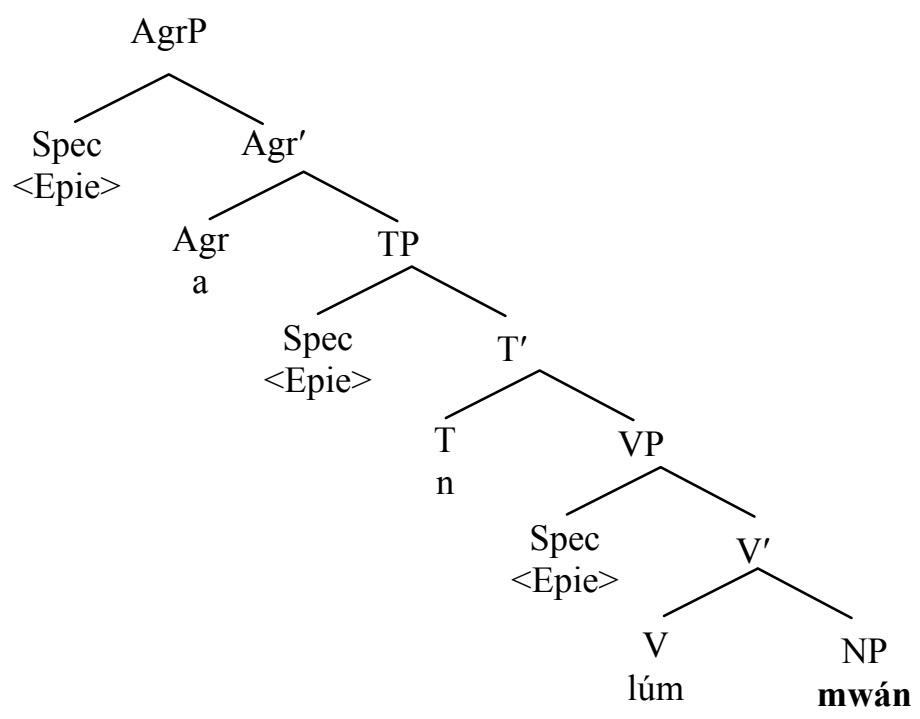

Recall that LLvs in Akoose are inherently finite and once introduced into a structure, the main verb is stripped of its finiteness. The infinite verb in turn loses its ability to assign case to its object, thereby rendering the visible noun caseless. This presumably explains why the object shifts to the light verb projection. Once in this position, it receives accusative case from the light verb, as shown in (17a, and 17b).

(17) a. Epie a yóké mwán ${ }_{\mathrm{i}}$ a-lúm ti

Epie agr often child to send

"Epie often sends the child".

b.

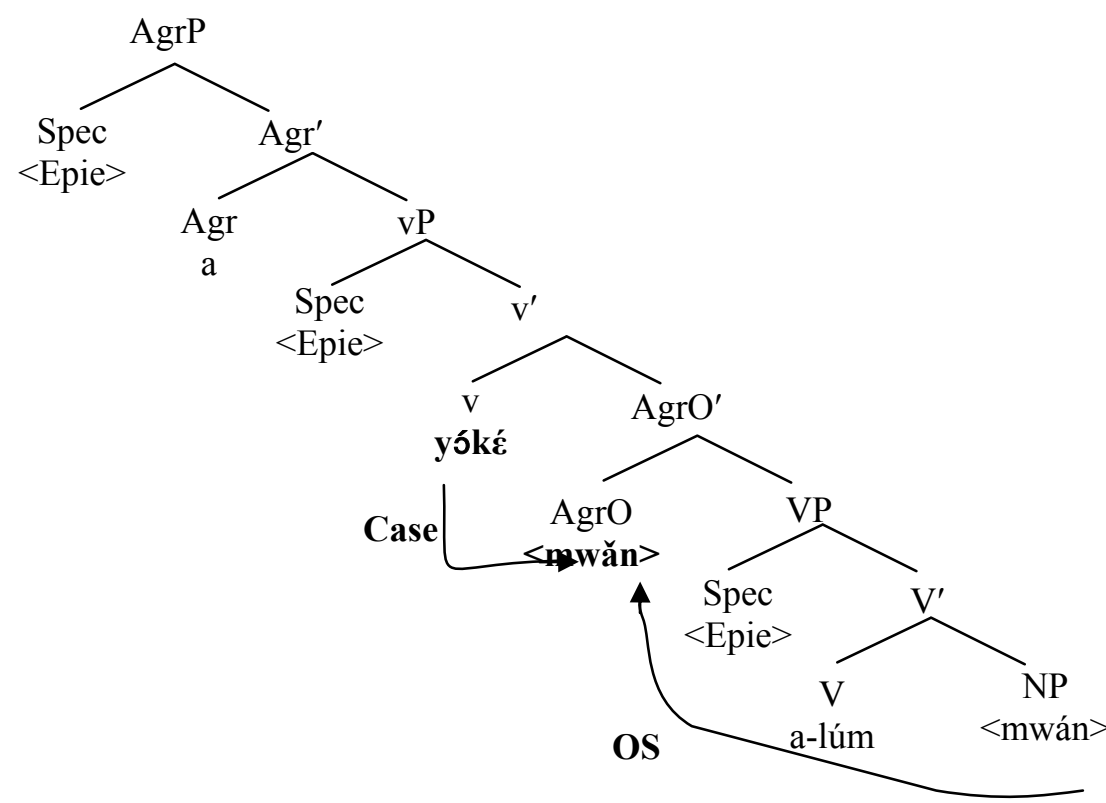

An alternative analysis can possibly throw more light on the foregone argumentation. Supposing it is claimed that the object raises to AgrO even without the introduction of a LLv then an ill-formed structure like the one in (18) is derived. The culprit movement is shown in (18b).

(18) a. *Epie a $n$ mwán ${ }_{\mathrm{i}}$ lúm $\mathrm{t}_{\mathrm{i}}$ 
Epie sm P1 child send

b.

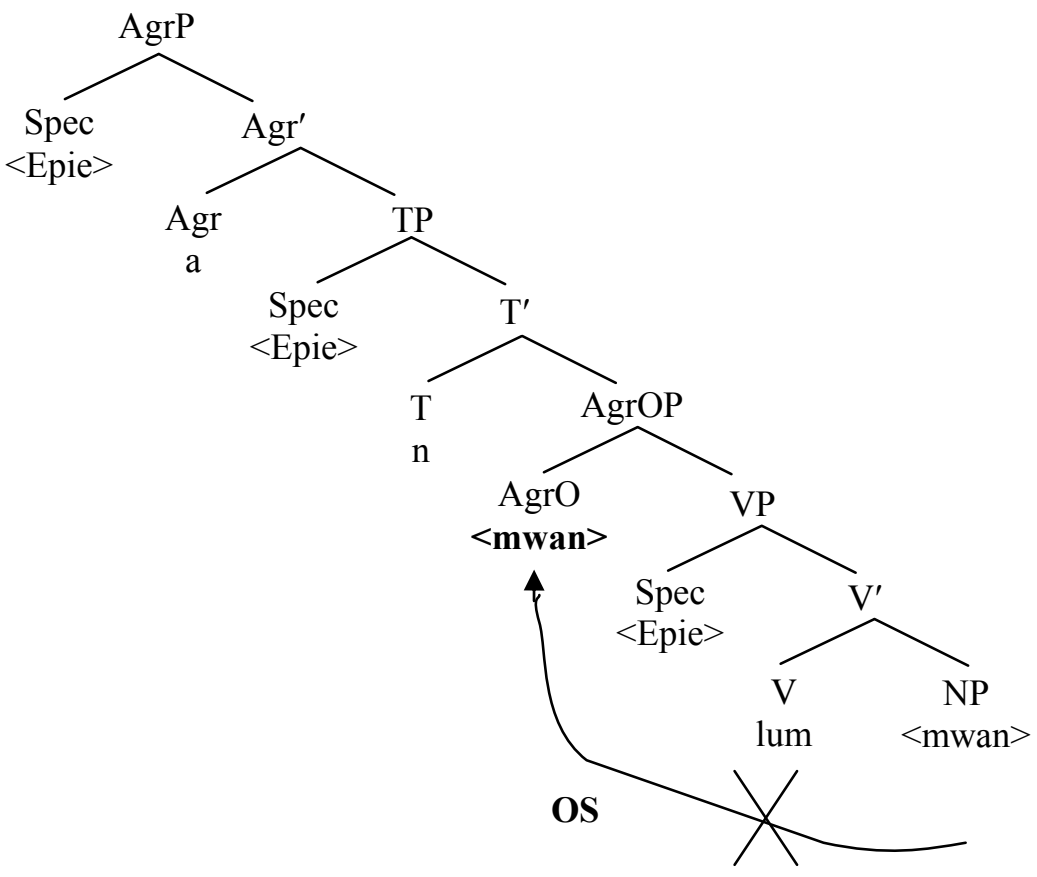

The ungrammaticality of (18) presupposes that OS is licensed only when the LLv is visible in a construction. Arguably, therefore, case deficiency is apparently crucial to object shift in Akoose.

However, if infinitives can take objects in some languages as illustrated with data in English, it means that the structure in (19) may not just be as a result of case deficiency. By extension, if an NP in Akoose is forced to move because it fails to receive case from its c-commanding verb, it presupposes that there is more to it than just case deficiency.

(19) a. *Epie a yóké a-lúm mwán

Epie agr often to send child

b. *Epie a yóké lúm mwán

Epie agr often send child

Considering the fact that the data in (19) exhibit the LLv without OS, one begins to wonder how the ungrammaticality of these structures can be explained. The logical thing to do now is to further determine whether or not the strictures of the Theta $(\theta)$ theory and the Case theory for instance, adequately handle these cases. Certainly, the Case filter will be able to predict that the object in (19a) does not receive case from its c-commanding verb because it is non-finite, but it is silent on the presence of the LLv in the structure. Again, the filter will wrongly rule in ill-formed (19b) given that the object apparently receives case from its c-commanding, conjugated verb. This implies that the case filter does not adequately account for these structures.

Consider a $\theta$-role account. According to Williams (1994), preserving $\theta$-role assignment possibilities must be open given that $\theta$-role is subject to absolute (sister) locality and $\theta$-role directionality parameter setting, which determines the $\theta$-role assignment configuration. The $\theta$-criterion would correctly rule out (17) given that in (17a) the legitimate verb to $\theta$-mark the object is not local to the latter, and (17b) is an outright violation of 
the $\theta$-criterion given that the object receives two thematic roles. In other words, a light verb has been introduced when the main verb is still finite, or the latter does not lose its finiteness despite the introduction of a light verb; hence the object ntid receives two thematic roles. However, despite the apparent elegance of the $\theta$-criterion on these examples, it does not also sufficiently explain how OS fails to take place in the same structures.

The challenge now is to examine the data from the standpoint of the Minimalist Program. Two different analyses are possible here, the first one focuses on the strong inflected features of the LLv, and the other is based on uninterpretable features of the object NP. Given that LLvs carry strong morphological features that must be valued and deleted for convergence; their presence in a sentence usually affects the syntax such that the relevant morphological categories are satisfied. This is done by the post-verbal object raising to the LLv projection. The object then values and deletes the strong features of the LLv. However, note that the data in (19) shows that the object has not moved. With this, two questions emerge: (1) what conditions OS? (2) What blocks OS? In both (17a) and (17b), a VP intervenes between the object and the LLv. However, whereas the intervening VP in (17a) is an infinitive verb, the one in (17b) is finite. Nevertheless, what is crucial is that the intervening VP blocks the movement of the object.

Recent minimalist approaches point to the fact that agreement triggers movement (Miyagawa, 2010). It is further argued here that light verbs unlike infinitive verbs in Akoose have strong, uninterpretable features that must be valued for convergence. LLvs therefore trigger the movement of the post verbal object to the AgrO projection, a position in which valuation is satisfied, as illustrated in (20). Concretely, when mwan moves to AgrO, it functions as the object of the light verb; hence the features of the LLv are valued by the object.

(20)

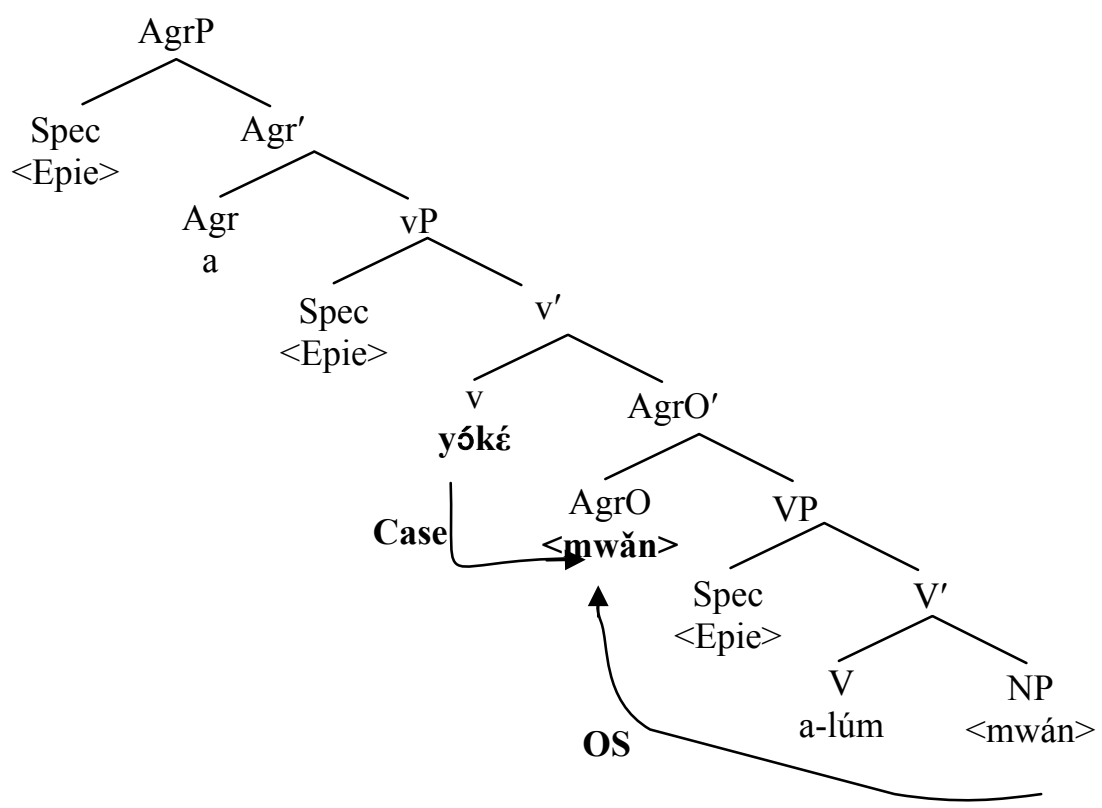

According to Miyagawa (2010) further, heads select their complements; movement brings the goal close to the probe, and movement must be justified where agreement is concerned. In (21), the head, yók does not select its complement, mwan, due to the intervention of a VP.

(21) 


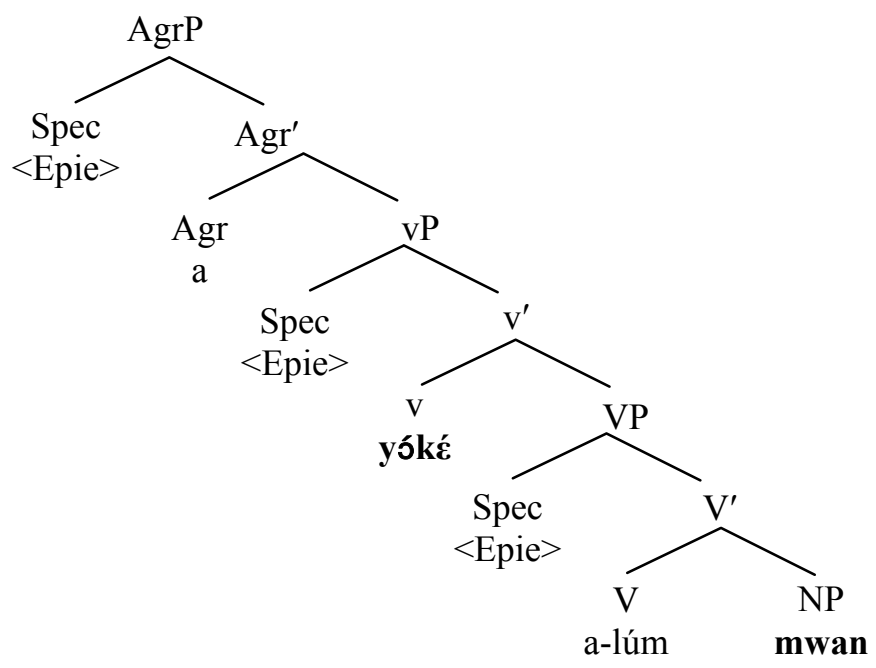

This presupposes that agreement between the goal and the probe, which must be local for the relevant uninterpretable features to be valued, is violated, as predicted by the Locality Principle, stated in (22).

(22) Locality Principle

One constituent $\mathrm{X}$ can agree with another constituent $\mathrm{Y}$ if $\mathrm{Y}$ is in the local c-command domain of $\mathrm{X}$-i.e. only if $\mathrm{Y}$ is c-commanded by $\mathrm{X}$ and if $Y$ is sufficiently close to $X$ (Chomsky, 1995).

In other words, the goal, "mwan" does not enter into any agreement relation with the probe, " $y$ ok $\varepsilon^{\prime}$ " in (21) as required because the probe is not sufficiently close to its matching goal. As a result, the uninterpretable specifier features of the probe remain unvalued. This therefore rules out the structure for grammaticality.

Following the reasoning that infinitives do not assign case to their objects in Akoose, it is assumed also that they cannot value the uninterpretable case features of the same, in the minimalist sense. This explains the reason for OS each time an object is preceded by a non finite verb. Since the LLv has finite features with which the uninterpretable features of the object can be valued and deleted, the object is obliged to move.

According to Miyagawa (2010), one of the greatest mysteries of human language is the existence of movement operations on the one hand and the occurrence of agreement in natural language on the other. Noting that the content of the agreement system sometimes appears patently random, as for example in assigning gender to noun phrases (in addition to the fact that whereas some languages have agreement others do not). Miyagawa (2010) assumes that movement and agreement interact in a meaningful way to substantially enhance the expressive power of human language. Miyagawa (2010) further notes that the purpose of agreement is independent of the content of agreement-it is to establish a functional relation between a functional head and an XP. Like the Koopman-Sportiche intuition therefore, he assumes that agreement requires a Spec-head relation by showing that Agree takes place to establish functional relations. It is further maintained that this functional relation that is always nonlocal, must be transformed into a local relation by moving the goal to the probe.

In terms of edge features, Miyagawa asserts that Chomsky's (2007) suggestion that the edge feature is responsible for both external and internal Merge blurs the distinction between lexical and functional relations. $\mathrm{He}$ also notes that the edge feature is independent of Agree, and that it brings us back to something akin to 
Government and Binding (GB) in a way, where free movement - free internal Merge - to any head is allowed. In essence, therefore, Miyagawa holds that movement must be justified where agreement is concerned, and that movement brings the goal close to the probe. In the probe-goal pair therefore, agreement is invoked in the sense that the $\phi$-probe is the uninterpretable feature that must be valued by the interpretable feature on the goal.

From the foregoing arguments, it is assumed that movement (V-movement, A-movement and $\mathrm{A}^{\prime}$-movement) in Minimalist terms has a single purpose, namely to value the uninterpretable features. Actually, unlike GB, a uniform account of the theory of movement seems to be achieved ${ }^{2}$.

This data analysed in this paper support Miyagawa's (2010) arguments on movement and agreement, as well as Ouhalla' (1999) correlation between V-raising and OS.

\section{Conclusion}

Discussions in this paper were centered on A-movement and verb raising, with the aim of determining whether OS in Akoose is due to case deficiency or agreement requirements. The analysis shows that case deficiency accounts for only certain structures in the language. For instance, the Case Filter can predict that the object in a given structure does not receive case from its c-commanding verb because it is non-finite, but it will be silent on the presence of the LLv in the structure. Again, the filter wrongly rules in some ill-formed sentences, which nevertheless shows that the object receives case from its c-commanding, conjugated verb. This presupposes that OS poses problems to the Case Filter.

However, the problem created by OS in the language is presumably solved, following recent minimalist approaches, wherein agreement plays a key role in the analysis. As a result, it is argued that agreement requirements in light verb constructions in Akoose trigger OS; the stance that agreement is crucial to OS in Akoose is further supported by the data and empirical evidence, which points to the conclusion that agreement is blocked in structures that run afoul, i.e. where OS is not possible in complex VP structures. Evidently, therefore, uninterpretable features are not valued in such ungrammatical constructions. Given that agreement links the probe and its goal via movement, in structures where agreement relations hold in Akoose, uninterpretable features of the relevant syntactic objects are valued for convergence.

\section{References}

Chomsky, N. (1981). Lectures on government and binding. Dordrecht: Foris.

Chomsky, N. (1995). The minimalist program. Cambridge, MA: MIT Press.

Chomsky, N. (2000). Minimalist inquiries: The framework. In R. Martin, D. Michaels, and J. Uriagereka (Eds.), Step by step (pp. 89-155). Cambridge, MA: MIT Press.

Chomsky, N. (2001a). Beyond explanatory adequacy. MIT Occasional Papers in Linguistics 20. Cambridge, MA: MITWPL.

Chomsky, N. (2001b). Derivation by phase. In M. Kenstowowicz (Ed.), Ken Hale. Cambridge, MA: MIT Press.

Cook, V. J., \& Newson, M. (2007). Chomsky's universal grammar: An introduction. Blackwell Publishing.

den, B. (1983). On the interaction of root transformations and lexical deletive rules. In W. Abraham (Ed.), On the formal syntax of the Westgermania. Amsterdam: John Benjamins.

Hedinger, R. (2008). A grammar of Alkoose: A northwest Bantu language. SIL.

Holmberg, A. (1986). Word order and syntactic features in the Scandinavian languages and English. Ph.D. thesis, Stockholms Universitet.

\footnotetext{
${ }^{2}$ Following Cook and Newson (2007), movement served no purpose in GB as it does in the MP; rather it achieved grammatical structures for different reasons: V-movement allowed structure to be grammatical by getting the verb and the inflection together to satisfy the morphological requirements of the inflection; A-movement enabled DPs to achieve case positions, hence satisfying the Case Filter and A'-movement seemed to satisfy certain semantic requirements placed on structure.
} 
Holmberg, A. (1999). Remarks on Holmberg's generalization. Studia Linguistica, 53, 1-39.

Koopman, H. (1984). The syntax of verbs. Dordrecht: Foris.

Lightfoot, D., \& Hornstein, N. (1994). Verb movement. Cambridge: Cambridge University Press.

Miyagawa, S. (2010). Why agree? Why move? Unifying agreement-based and discourse-configurational languages. Massachusetts: MIT.

Ouhalla, J. (1999). Introducing transformational grammar: From principles and parameter to minimalism. London: Edward Arnold.

Torrego, E. (1984). On inversion in Spanish and some of its effects. Linguistic Inquiry, 15, 103-129.

Travis, L. (1984). Parameters and the effects of word order variation. Ph.D. dissertation, MIT.

Vikner, S. (1991). Relative der and other C. elements in Danish. Lingua, 84, 9-136.

Williams, E. (1994). Thematic structure in syntax. Cambridge: MIT Press. 